\title{
Two-hour Adrenocorticotropic Hormone Test: Accuracy in the Evaluation of the Hypothalamic- Pituitary-Adrenocortical Axis
}

\author{
SEPPO LEISTI(4) AND JAAKKO PERHEENTUPA
}

The Children's Hospital, University of Helsinki, Helsinki, Finland

\section{Summary}

The inter- and intraindividual variations of response to an iv bolus of tetracosactide $\left(0.25 \mathrm{mg} / 1.73 \mathrm{~m}^{2}\right)$ were studied, and a definitive diagnostic 2-hr test was established. The test was given to 179 subjects: hypopituitary, prednisone-treated nephrotics, patients with the autoimmune polyendocrinopathycandidiasis syndrome (APECS), and reference subjects. It was repeated in 62 cases and the total of 84 test pairs was analyzed. The test was started either at 8-9 AM or at 10-11 AM, 2 hr after the injection of insulin for an insulin test. Thirty subjects had both the ACTH test and the insulin-ACTH test. Capillary blood samples for fluorometric determination of plasma cortisol were taken 1,2 , and $3 \mathrm{hr}$ after the injection.

The distributions of the basal and stimulated levels were positively skewed, and $\log$ transformation of the data gave clearly more appropriate statistics. In most subjects the cortisol level was highest 2 hr after the injection. There was no significant difference in the response to ACTH whether it was given alone or in the insulin-ACTH test. All the poststimulation cortisol levels showed a positive interindividual correlation with the basal levels, and all the increments a negative interindividual correlation with the basal levels.

In repeated tests, the intraindividual variation in the responses was directly correlated with the level of the response, and this correlation could be removed by dividing the intrapair difference in the values of the parameters by the sum of the values for percentage of intrapair difference (PIPD). The SD of the distribution of PIPDs was used for an index of precision. The 2hr cortisol level was substantially more precise than either the basal level or the increment. In analysis of correlation between PIPDs, variation of the 2-hr level showed no significant dependence on the variation of the basal level, but the variation of the 2-hr increment was highly dependent on the variations of both the basal level and the 2 -hr level. Thus the 2 -hr plasma cortisol level is the best single index of the response. A better definition of normal result is given by a reference area on a plot of 2-hr level versus basal level (Fig. 2.).

Of 31 tests given to hypopituitary subjects with deficient cortisol responses to insulin, all but 7 gave subnormal basal and/ or 2-hr levels. In 8 the increment was also subnormal. In the nephrotic subjects, all but one of 36 tests given at the end of continuous prednisone medication gave subnormal basal and/or 2-hr levels; the increment was subnormal in 26 . At the end of the following period of intermittent prednisone, 12/36 tests gave normal results and none failed to elicit a response. The increment remained subnormal in 6 despite normal basal levels.

A high normal response to ACTH was constantly associated with a normal response to insulin, and was thus indicative of normal ACTH secretion. In the reference subjects, there was a highly significant correlation between the responses to insulin and ACTH. The mean \pm SD of PIPDs between these responses was $-9.2 \pm 13.2 \%$. Of the APECS patients, seven with incipient adrenocortical failure had a normal increment despite subnormal basal and stimulated levels. Thus the ACTH test did not differentiate this state from ACTH deficiency.

\section{Speculation}

When the criteria for a normal finding in the 2-hr iv ACTH test have been carefully established, this test will serve as a definitive procedure for the diagnosis and follow-up of states associated with ACTH deficiency, as well as in primary diseases of the adrenal cortex. Like the other ACTH tests, however, it will not differentiate with certainty between primary and secondary adrenocortical failure.

In the diagnosis of adrenocortical failure, stimulation with a single dose of exogenous ACTH with determination of the response in plasma cortisol level has partly replaced longer tests. The shortest test in wide use consists of an im or iv injection of the $1-24$ peptide $(20,24,38)$ and determination of plasma cortisol before and $30 \mathrm{~min}$ after the injection $(4,11,18,37,39$, 41). However, this test is not accurate, and it is used mainly as a screening procedure, with variable criteria for a normal response. In none of the 1 to 3 -hr tests so far introduced have criteria for a normal response been adequately established on a theoretically sound basis $(23,31-33,35,42)$. We have made a careful evaluation of a 2-hr ACTH test, which we here propose for a definitive diagnostic procedure. A preliminary report has appeared (28).

\section{MATERIALS}

A total of 179 subjects 2.0-25 years of age were investigated, 133 of them for short stature or suspicion of hypopituitarism. Of these, 73 subjects ( 25 with familial short stature, 21 with delayed growth and maturation, 14 with prenatal growth failure, 8 with chromosome aberration, and 5 with skeletal dysplasia) were shown to have normal secretion of pituitary hormones (GH, ACTH, TSH, and ADH), and reference values for the test were calculated from their data. The other 60 subjects were hypopituitary: 19 had isolated GH deficiency, 41 had combined and/or organic hypopituitarism, 13 did not have and 28 had ACTH deficiency. The latter was diagnosed if the plasma cortisol response to insulin was repeatedly subnormal. There were 22 patients with hypothalamic tumor or hemorrhage.

Twenty-one children with "minimal change" idiopathic nephrotic syndrome (INS) in relapse (8) were studied to evaluate the effect of pharmacologic prednisone medication on the results of the ACTH test. Nine of them had two to four relapses during the study, and a total of 36 treatments were analyzed. An ACTH test was given 1-3 days after the end of 6-28 days' continuous medication (1) $\left(60 \mathrm{mg} / \mathrm{m}^{2}\right.$ daily in three doses $)$, another 4-6 days after the end of subsequent intermittent medication $\left(40 \mathrm{mg} / \mathrm{m}^{2}\right.$ in three doses on Tuesdays, Wednesdays, 
and Thursdays for 4 weeks). Sixteen tests were done during continuing remission 6 months later in 14 patients.

Twenty-five subjects with APECS $(7,36)$ were tested to detect primary adrenocortical disease; 8 of them were followed with a total of 42 tests during the progression of the disease.

Cortisol substitution $\left(7.5-15 \mathrm{mg} / \mathrm{m}^{2}\right.$ daily) had been given before the tests to 11 of the patients with tumors and to 8 of the patients with APECS. It was discontinued on the preceding day.

To establish its precision, the test was repeated in 62 subjects (36 reference subjects, 20 hypopituitary, and 6 APECS patients, none of them on cortisol substitution). Fourteen subjects underwent more than two tests, making 84 test pairs. There were 33 test pairs with a "short" interval (4-10 days during the same hospitalization) and 51 pairs with a "long" interval (0.1-2.2 years). None of the latter were in subjects with a progressive disease.

\section{METHODS}

\section{ACTH TEST}

Synthetic tetracosactide (S-Cortrophin, N. V. Organon, Oss, The Netherlands) (20) was given as an iv bolus injection at 8-9 AM, $0.25 \mathrm{mg} / 1.73 \mathrm{~m}^{2}$. Capillary blood samples were taken before and 1,2 , and $3 \mathrm{hr}$ after the injection. Thirty-one reference subjects had the test according to this protocol.

\section{ACTH TEST AFTER INSULIN TEST (INSULIN-ACTH TEST)}

An identical injection of tetracosactide was given at 10-11 AM, $2 \mathrm{hr}$ after the injection of insulin for the insulin test, through a venous cannula left in place after injection of insulin; $2 \mathrm{hr}$ later a capillary blood sample was taken for determination of plasma cortisol level. The basal cortisol level measured for the insulin test was taken as the basal level for the ACTH test. Forty-two reference subjects were given the ACTH test according to this protocol. In most of these tests, $5 \% 1$-arginine- $\mathrm{HCl}$ solution, $10 \mathrm{ml} / \mathrm{kg}$, was given as a $30-\mathrm{min}$ iv infusion $60-90 \mathrm{~min}$ after the insulin injection.

\section{INSULIN TEST}

Regular porcine insulin, $4.0 \mathrm{IU} / \mathrm{m}^{2}$, was given after an overnight fast as bolus injection through a venous cannula, after a rest of at least $30 \mathrm{~min}$ after insertion of the cannula. Blood samples for glucose and cortisol determinations were taken basally, and half-hourly for $2 \mathrm{hr}$. The maximal cortisol level at any time during the test was the index of cortisol response, this being the most accurate parameter of the test in children (12, $17,25,26)$.

\section{PLASMA CORTISOL}

The concentration of 11-hydroxycorticosteroids in plasma was determined with an ultramicromodification of a two-point fluorometry method (40), which is not subject to interference from cholesterol, cholesterol esters, or triglycerides. The values are expressed as cortisol, but include corticosterone. The betweenassay variation of the method was determined by measuring three standard plasma samples in $30-44$ consecutive assays. The coefficients of variation were $5.4 \%$ for the mean concentration of $14.8 \mu \mathrm{g} / 100 \mathrm{ml}, 2.6 \%$ for $36.1 \mu \mathrm{g} / 100 \mathrm{ml}$, and $1.4 \%$ for $71.8 \mu \mathrm{g} / 100 \mathrm{ml}$. For within-assay variation two plasmas were measured; the coefficient of variation was $2.1 \%$ for $25.2 \mu \mathrm{g} /$ $100 \mathrm{ml}$ and $1.6 \%$ for $32.3 \mu \mathrm{g} / 100 \mathrm{ml}$. The accuracy of this method was assessed by comparison with a cortisol-binding globulin radioassay of cortisol (34). In a series of 10 plasma samples (concentration range according to the cortisol-binding globulin assay $0.4-20.3 \mu \mathrm{g} / 100 \mathrm{ml}$ ) the equation of regression of the fluorometric result $\left(C_{t}\right)$ on the cortisol-binding globulin assay result $\left(C_{c}\right)$ was $C_{f}=5.1+1.35 C_{c}(r=0.92, P<0.001)$.

\section{CALCULATIONS AND DEFINITIONS}

The distributions of the cortisol levels and increments were positively skewed and log transformations of the data were made to obtain more meaningful means and confidence limits $(16$, 19). Regression lines and confidence limits for the estimation of dependent variables were calculated with standard techniques (3).

For convenience, the term "normal" is used for values within the $95 \%$ confidence range of the reference series, and "subnormal" for values below that range

The precisions of the different parameters were calculated from the distribution of individual intrapair differences in the repeated tests. These differences were larger in the higher response area, and for standardization were expressed in percentage of the sum of the values of the parameter. If a is the parameter in the first test, and $b$ the parameter in the second test, the PIPD is $100(b-a) /(b+a)$. We express the precision of any test parameter as the SD of the distribution of PIPDs in a series of subjects.

The response to ACTH and insulin were compared in two different ways. Firstly, concordance or discordance between the two responses regarding normality/subnormality was observed. Secondly, an analysis of the difference between the two responses was made as described above for the difference between the first and second responses to ACTH (the response to ACTH was taken for $a$ and the response to insulin for $b$ in the formula given above). The mean and SD of the PIPDs was calculated for the reference series. Discordance between the two responses was defined as a difference exceeding the $90 \%$ confidence interval of the reference series.

Coefficients of interindividual correlations were calculated between untransformed values of the test parameters. Coefficients of intraindividual correlations were calculated between the PIPDs of the parameters.

\section{RESULTS}

\section{ACTH TEST ALONE VERSUS INSULIN-ACTH TEST}

The statistics of the basal and 1- to 3-hr plasma cortisol levels and increments are given in Table 1 . Of the 31 reference subjects who were given ACTH test alone, 4 had the maximal level at $1 \mathrm{hr}$ and 27 at $2 \mathrm{hr}$.

The 2-hr level was chosen for the index for further analysis of the response. Forty-two other reference subjects had the insulinACTH test. This ACTH test series did not differ significantly from the previous one in any parameter, although the basal cortisol levels tended to be slightly higher (Table 1). Thirty subjects had both the ACTH test alone and the insulin-ACTH test (Fig. 1). The responses did not differ significantly $(t=0.33$ for $29 \mathrm{df})$ and showed a significant correlation $(r=0.80$, $P<0.001)$. Thus, the two series were combined for definition of the normal test result.

\section{INTERINDIVIDUAL VARIATION IN RESULTS OF ACTH TEST:} INTERDEPENDENCE OF PARAMETERS

All three poststimulation plasma cortisol levels measured were positively correlated with the basal level $(r=0.30-0.57$, $P<0.05)$, but all increments were negatively correlated with the basal level $(r-0.58$ to $-0.46, P<0.01)$; these correlations were similar in the two series of tests. The regressions of the 2$\mathrm{hr}$ level and of the 2-hr increment on the basal level are shown in Figure 2. The latter regression is not truly linear, as the increments were disproportionately low at high basal levels. This suggests that the high basal levels depend on near-maximal stimulation of the adrenal cortex by endogenous ACTH. The $2-$ $\mathrm{hr}$ level and increment showed a mutual positive correlation $(r=0.50, P<0.01)$. 
Table 1. ACTH test in reference subjects ${ }^{1}$

Cortisol levels Cortisol increments

\begin{tabular}{|c|c|c|c|c|c|c|c|}
\hline & & & & & & & \\
\hline & Basal & $1-\mathrm{hr}$ & $2-\mathrm{hr}$ & $3-\mathrm{hr}$ & 1-hr & $2-\mathrm{hr}$ & 3-hr \\
\hline $\begin{array}{l}\text { ACTH test alone ( } n= \\
\text { 31) }\end{array}$ & $\begin{array}{c}21.2 \\
(10.1-44.6)\end{array}$ & $\begin{array}{c}43.8 \\
(31.6-60.7)\end{array}$ & $\begin{array}{c}48.0 \\
(33.8-68.4)\end{array}$ & $\begin{array}{c}37.5 \\
(23.9-58.9)\end{array}$ & $\begin{array}{c}20.4 \\
(9.1-46.0)\end{array}$ & $\begin{array}{c}24.2 \\
(10.1-58.4)\end{array}$ & $\begin{array}{c}12.7 \\
(2.4-68.2)\end{array}$ \\
\hline $\begin{array}{l}\text { Insulin-ACTH test ( } n \\
\quad=42)\end{array}$ & $\begin{array}{c}23.0 \\
(13.1-44.8)\end{array}$ & ND & $\begin{array}{c}49.1 \\
(34.1-70.1)\end{array}$ & ND & ND & $\begin{array}{c}23.7 \\
(10.1-55.6)\end{array}$ & ND \\
\hline Both series $(n=73)$ & $\begin{array}{c}22.4 \\
(11.6-43.4)\end{array}$ & ND & $\begin{array}{c}48.6 \\
(34.3-69.0)\end{array}$ & ND & ND & $\begin{array}{c}24.0 \\
(10.4-55.3)\end{array}$ & ND \\
\hline
\end{tabular}

' Means and $95 \%$ confidence ranges for plasma cortisol (micrograms per $100 \mathrm{ml}$ ), calculated on a log scale for 31 subjects who had an ACTH test alone, and for 42 subjects who had an insulin-ACTH test. ND: not determined.

BASAL CORTISOL 2-h CORTISOL

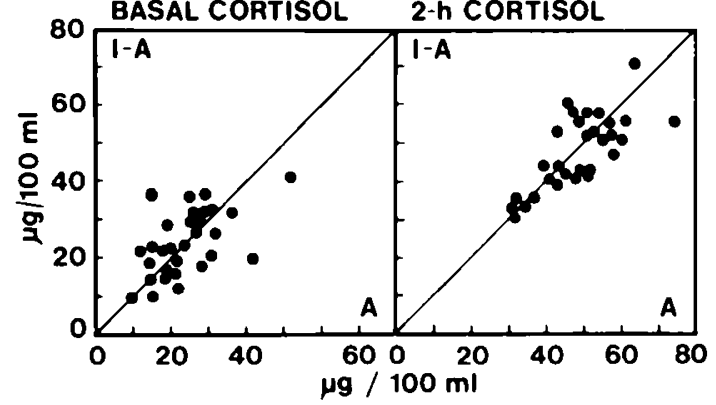

Fig. 1. The relation between the results of a 2-hr ACTH test when performed alone (A) and immediately after an insulin test (I-A). The basal and 2-hr plasma cortisol levels in I-A have been plotted against the corresponding values obtained in $\mathrm{A}$ for 30 subjects who had both tests. The diagonals are the identity $(y=x)$ lines. For statistics see Table 1 .

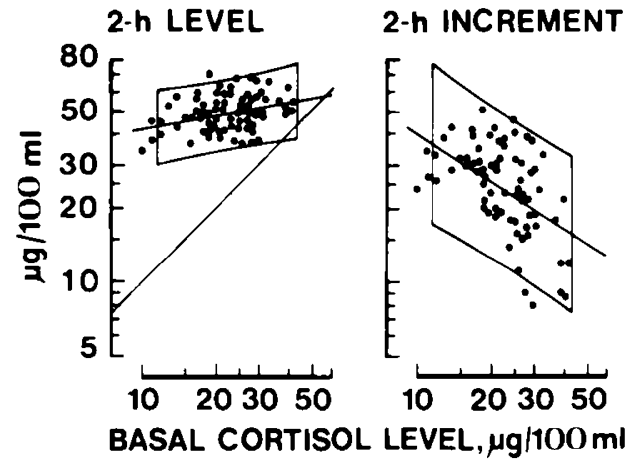

Fig. 2. Log scale scatter diagrams of 2-hr levels and 2-hr increments of plasma cortisol against the basal levels in ACTH tests of the 73 reference subjects. The diagonals are the regression lines, and the identity $(y=x)$ line in the first diagram. Areas of normal result are formed by the $95 \%$ confidence limits for the estimation of the dependent variable for given values of the basal level, and by the $95 \%$ confidence limits for the basal levels.

\section{INTRAINDIVIDUAL VARIATION IN RESULTS OF ACTH TEST: PRECISION OF PARAMETERS}

The reproducibility of the test parameters is illustrated in Figure 3 and the statistics of the test pairs are given in Table 2 . The variation in the response was clearly directly correlated with the level of the response, and the correlation could be removed dividing the intrapair differences by the intrapair sum of the values for PIPD.

The means of PIPDs were significantly different from zero for basal cortisol level and 2-hr increment in all test pairs and in the pairs of insulin-ACTH tests. There was a mean decrease in the basal level and a mean increase in the increment from the first to the second test. The means of PIPDs of the 2-hr level did not differ significantly from zero.

In their statistics, the pairs with a short interval between the tests did not differ from those with a long interval. The PIPDs showed no correlation with the age of the subjects or with the interval between the tests. The 2-hr cortisol level was substantially more precise than either the basal level or the increment. Thus the 2-hr level is the best single index of the response. Because of the interindividual dependence of the 2-hr level on the basal level, the normal result is best defined by a reference area on a plot of 2 -hr levels versus basal levels (Fig. 2).

\section{INTRAINDIVIDUAL VARIATION OF ACTH TEST: INTERDEPENDENCE OF PARAMETERS}

To assess how much of the variation in the three parameters in repeated tests was interdependent, the correlations between their PIPDs were analyzed (Fig. 4). The 2-hr level showed no significant correlation with the basal level. This means that, although the interindividual variation in the 2-hr level depended on the respective variation in the basal level, the intraindividual variation in the 2-hr level did not depend on the variation in the basal level. The 2 -hr increment showed a highly significant negative correlation with the basal level, and the two 2-hr parameters showed a positive correlation. The variation of the 2 -hr increment was totally dependent on the variations in the basal and 2-hr levels.

\section{DIAGNOSTIC ACCURACY OF ACTH TEST IN HYPOTHALAMIC-}

PITUITARY-ADRENOCORTICAL (HPA) AXIS HYPOFUNCTION

An analysis of $63 \mathrm{ACTH}$ test findings in the 60 hypopituitary children is presented in Figure $5 A$. Of the 19 subjects with isolated $\mathrm{GH}$ deficiency, 18 gave results within the reference area. The remaining subject had an abnormally high basal level. Of the 13 cases of combined and/or organic hypopituitarism with normal cortisol response to insulin, 11 gave a result within the reference area, and 1 patient had a slightly subnormal basal level. Only 1 subject had a clearly subnormal response suggesting secondary adrenocortical failure.

Of 31 ACTH tests given to 28 hypopituitary subjects with ACTH deficiency, 7 gave results that fell within reference area and all the others, including the tests of the 11 receiving cortisol substitution, gave subnormal values for the basal level and/or the 2-hr level. In 8 of these tests there was also a subnormal increment, and 5 of them were in patients receiving cortisol substitution.

Figure $5 B$ shows the effect of pharmacologic prednisone medication on the ACTH test result in 21 subjects with INS. Of the 36 tests done at the end of continuous prednisone medication after a relapse, all but 1 gave subnormal results. The increment was also subnormal in 26 of the tests. At the end of intermittent prednisone medication the situation had changed substantially. Twelve of 36 tests were within the reference area and no test failed completely to elicit a response. Nonetheless, 7 tests gave subnormal increments although in 6 of these basal levels were normal. This suggests a near maximal stimulation of the adrenals by endogenous ACTH at this time, a finding similar to that in patients with moderate or severe primary adrenocortical failure. Of 16 tests done 6 months after the medication, 13 gave results 


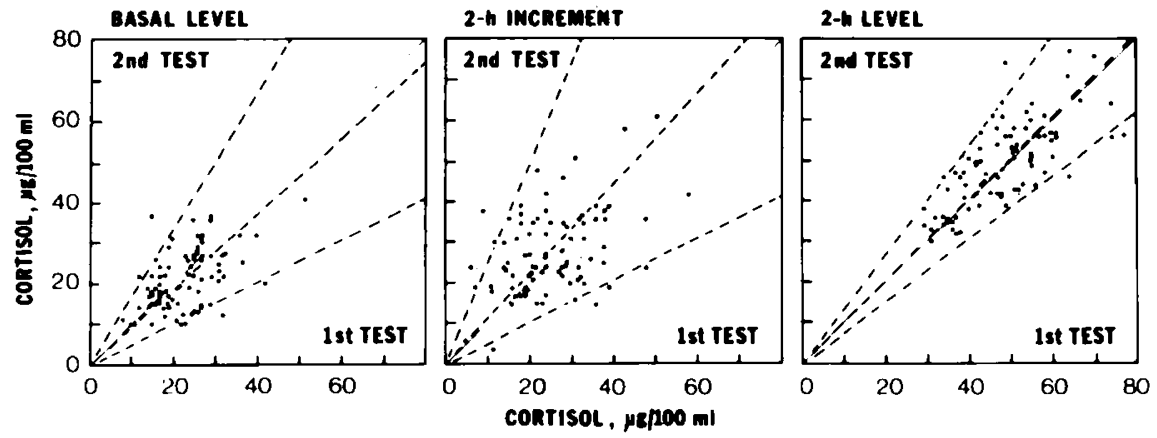

Fig. 3. Precision of three parameters of the 2-hr ACTH test. The values of the parameter at the second test have been plotted against those obtained at the 1 st test, for 84 pairs of (repeated) tests. The dashed lines give the means and $\pm 90 \%$ confidence limits for PIPDs (see Methods). The continuous diagonal is the identity $(y=x)$ line (intrapair difference $=0$ ). The means of the basal cortisol level and the 2-hr increment are significantly $(P<0.05)$ different from zero. For the statistics see Table 2.

Table 2. Precision of parameters of plasma cortisol level in ACTH test ${ }^{1}$

\begin{tabular}{|c|c|c|c|c|}
\hline Test pair & No. of pairs & Basal level & 2-hr level & 2-hr increment \\
\hline I. A-A & 12 & $-0.7(12.6)$ & $2.2(9.7)$ & $5.2(18.4)$ \\
\hline A-IA & 30 & $1.3(16.9)$ & $-0.4(6.7)$ & $-2.2(22.9)$ \\
\hline IA-IA & 42 & $-8.3^{2}(17.5)$ & $1.4(8.6)$ & $10.4^{2}(21.7)$ \\
\hline II. Short interval & 33 & $-4.4(18.9)$ & $0.6(8.8)$ & $5.4(23.7)$ \\
\hline Long interval & 51 & $-3.3(16.1)$ & $1.0(7.7)$ & $5.0(21.4)$ \\
\hline III. All pairs & 84 & $-3.8^{2}(17.1)$ & $0.9(8.1)$ & $5.1^{2}(22.2)$ \\
\hline
\end{tabular}

1 Means (SDs) for the percentage of intrapair differences of repeated tests of 62 subjects. For calculations, see Methods. A: ACTH test alone; IA: insulin-ACTH test. For test intervals, short $=4-10$ days (test repeated during the same hospitalization), long $=0.1-2.2$ years.

${ }^{2}$ Significantly $(P<0.05)$ different from zero.

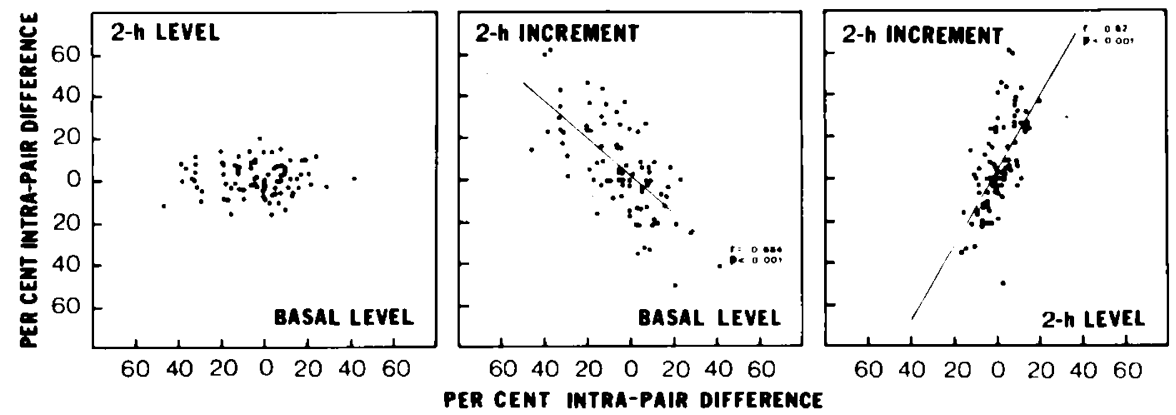

Fig. 4. An analysis of mutual interdependence of intraindividual variation in three parameters of the 2-hr ACTH test. The PIPDs in the parameters have been plotted against each other for 84 pairs of (repeated) tests. The differences in the 2-hr level showed no significant correlation with the differences in the basal level.

that fell within the reference area, whereas in 3 the basal cortisol level was still subnormal.

Primary adrenocortical failure will develop at some age in about half of the patients with APECS. Forty-two ACTH tests in 25 subjects with this syndrome gave various results (Fig. $5 C$ ). Nine results were within the reference area, indicating normal adrenocortical function. Seven results were outside the reference area, but with a normal increment. The remaining 26 tests. including 8 preceded by cortisol substitution, all revealed subnormal increments. In some of these patients, however, the exogenous ACTH did bring about a significant cortisol increment, irrespective of whether or not the basal level was low.

\section{COMPARISON OF RESPONSES TO ACTH AND INSULIN (FIG. 6)}

A high normal response to $\mathrm{ACTH},>45 \mu \mathrm{g} / 100 \mathrm{ml}$, was constantly associated with a normal response to insulin, and thus indicated normal ACTH secretion.

In the reference series (Fig. $6 A$ ) the two responses showed a significant correlation $(r=0.45, P<0.001)$. The lower limits of normal for the responses to ACTH and insulin were $34.3 \mu \mathrm{g} /$
$100 \mathrm{ml}$ and $25.7 \mu \mathrm{g} / 100 \mathrm{ml}$, respectively. The mean $\pm \mathrm{SD}$ of PIPDs between the two responses was $-9.2 \pm 13.2 \%$. The limits for a significant discrepancy between the two responses were PIPDs of $-31.4 \%$ (discrepantly low response to insulin) and $12.9 \%$ (discrepantly high response to insulin).

All subjects with isolated GH deficiency and 10 of those with combined and/or organic hypopituitarism were normal-normal (for ACTH and insulin responses, respectively) in response pattern (discrimination by the squares in Fig. 6). Twenty subjects of the latter category were subnormal-subnormal, 11 normal-subnormal, and 3 subnormal-normal. Of the nephrotics with prednisone medication 18 were subnormal-subnormal and 1 normal-normal at the end of continuous medication. At the end of the intermittent medication, 11 subjects were normalnormal, 7 subnormal-subnormal, 2 normal-subnormal, and 3 subnormal-normal. At the 6-month follow-up 11 subjects were normal-normal and 1 subnormal-normal.

In the comparison of the two responses by the PIPD method (discrimination by the diagonals in Fig. 6), 15 of the 44 subjects with organic and/or combined hypopituitarism had a discrepantly low response to insulin. Such a discrepancy was observed six times in the subjects with prednisone medication. 


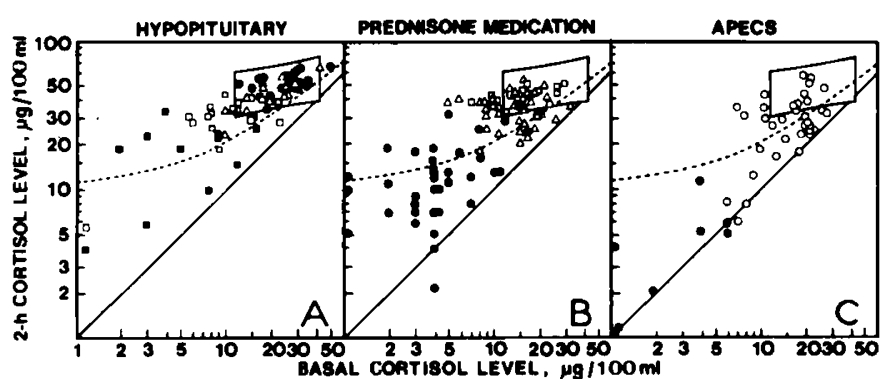

Fig. 5. An analysis of the results of the 2-hr ACTH test in three groups of patients with HPA axis deficiency. The figures are log scale scatter plots of the 2-hr plasma cortisol levels against the basal level. The area of normal result (see Fig. 2) is indicated by the quadrangle, and the minimum normal 2-hr increment $(10.4 \mu \mathrm{g} / 100 \mathrm{ml})$ by the curved dashed line (disregarding the dependence of the increment on the basal level). $A$; hypopituitary subjects: isolated $\mathrm{GH}$ deficiency $(\odot)$, combined and/or organic hypopituitarism with normal cortisol response to insulin $(\Delta)$, combined and/or hypopituitarism with deficient cortisol response to insulin, without $(\square)$ or with $(\square)$ previous cortisol substitution. $B$ : children with idiopathic nephrotic syndrome, at the end of 6-28 days' continuous prednisone medication $(\Theta)$, at the end of 4-week intermitten medication $(\triangle)$, and 6 months later in continuing remission ( $\square$ ). $C$ : subjects with APECS without $(O)$ and with $(0)$ previous cortisol substitution.

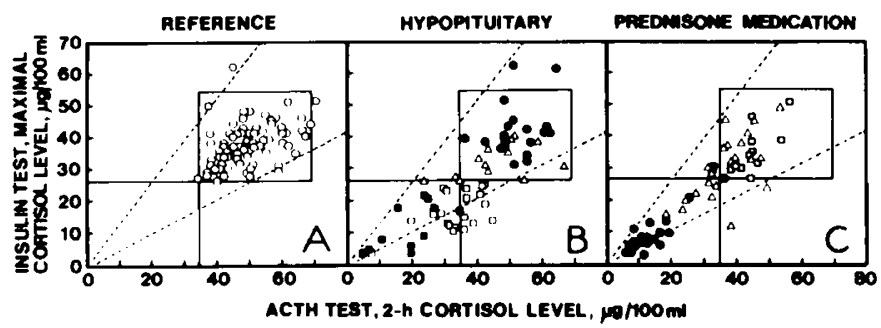

Fig. 6. Comparison between plasma cortisol responses to insulin and ACTH in three groups of subjects. The normal limits are indicated by quadrangles. The (dashed) diagonals give the $\pm 90 \%$ confidence limits for the PIPDs between the responses to ACTH and insulin in reference subjects. For definition of symbols of hypopituitary $(B)$ and prednisonetreated nephrotic subjects $(C)$ see figure 5 .

\section{DISCUSSION}

We chose the 2-hr plasma concentration as the index of response to a single injection iv ACTH test because it was the most precise of the parameters studied and the least dependent on the basal level. It is an approximate measure of the maximal level achieved (10), which seems to be a characteristic of individual subjects, and is largely independent of external factors. Thus we did not find any change in the response when the test was performed after an insulin test. The choice of this combined test saves time in the investigation of patients. A similar test has been used by Feurle et al. (15). The 2-hr test appears to be diagnostically superior to the commonly used 0.5 hr test $(41)$ and to the 1 -hr test $(23,31,33,35)$, and will often serve as a definitive diagnostic procedure, particularly for the combined insulin-ACTH test. We propose that the insulin test be routinely supplemented with this ACTH test. A high normal response (in our series, $>45 \mu \mathrm{g} / 100 \mathrm{ml}$ ) to the 2 -hr test indicates normal ACTH secretion; this simple test will thus often make the insulin test unnecessary. Recognition of the skewedness of distribution of basal and stimulated plasma cortisol levels is of importance, and log transformation of data of reference subjects is necessary for establishement of meaningful confidence limits of normality of response.

We have shown a postive interindividual correlation in our subjects between the basal and post-ACTH levels of plasma cortisol. Such a correlation can also be demonstrated in the data of refereno series published by others both for several-hour ACTH infusion $(13,24)$ and single dose stimulation $(2,4,6$, $11,14,37)$. This correlation was previously observed by Greig et al. (18). Birke and his coworkers (5) observed a similar correlation in the urinary excretion of cortisol metabolites after 8-hr ACTH infusion and allowed for it in establishing the criteria of a normal response. Such a correlation also appears in the 5-day metyrapone test (29). If the variation in the stimulated level were causally dependent on the variation in the basal level, the regression of the stimulated level on the basal level would have to be considered in defining the criteria. However, we have presented evidence against such a causal relationship. Analysis of the repeated tests showed that, intraindividually, the variation in the 2-hr level was not significantly dependent of the variation in the basal level. Presumably, the interindividual correlation between the stimulated and basal levels found in our reference series reflects a parallel dependence of both on a third factor, such as the general activity of the adrenal cortex in the individual subject. Nevertheless, we have found it very useful to employ response areas on a plot of stimulated versus basal level for the analysis of the test results. For comparison with responses to other types of tests, the 2-hr level is appropriate.

Previously, various criteria of response to single dose ACTH stimulation have been used. A minimum absolute increment was proposed by Wood et al. (41) in the introduction of the 30-min im test, and this criterion has been accepted by many (31-33, $35,39,42)$. The triple criteria of minima of basal level, stimulated level, and increment were proposed by Greig (18). Others have combined the minima of the two latter parameters $(4,11)$. Although the increment has been regarded as the most useful parameter of the response (18), we consider it to be of little value. It is a highly dependent variable, its intraindividual variation depending upon the variation of the basal and stimulated levels, the two latter being mutually independent. Furthermore, in our series, the increment was poor in precision as compared with the 2 -hr level. This is a consequence of the dependence of the increment on the basal level, which fluctuates markedly in children, presumably due to psychic and external physical factors, as evidenced by significantly higher levels in the first than in the second test in our series. However, absence of an increment is diagnostically significant as indirect evidence that endogenous ACTH secretion is highly stimulated. An increment is absent in moderate and severe primary adrenocortical disease, such as was present in some of our APECS patients and during recovery from suppression due to glucocorticoid medication.

Knowledge of the intraindividual precision of the test has two important practical applications. First, it follows from the normal variability that responses near the limits of a "normal response" are diagnostically uncertain. If a subject's (theoretic) characteristic response (mean of large number of responses) is exactly at the lower limit of normal, the single random responses will be symmetrically dispersed around this limit so that $90 \%$ of them fall in a zone with a width of the $90 \%$ confidence interval of PIPDs. If a random response is obtained just below this zone of uncertainty there is a $<5 \%$ probability that it represents an individual whose characteristic response is above the lower normal limit. Similarly, a response just above this zone of uncertainty may be taken as evidence of normality of response with a confidence of $>95 \%$. In the zone of uncertainty the risk of a diagnostic error is $>5 \%$. In our series this zone of uncertainty for the 2-hr cortisol level was 29.6-38.8 $\mu \mathrm{g} / 100 \mathrm{ml}$. A similar zone of uncertainty exists at the upper normal limit; for our series it was $60.0-78.8 \mu \mathrm{g} / 100 \mathrm{ml}$. Second, the precision serves to define the significance of a decrease (or increase) in the response of an individual subject who is being followed for an expected progression of (or recovery from) adrenocortical insufficiency. For example, progression was expected in a patient and the 2-hr cortisol level was $35 \mu \mathrm{g} / 100 \mathrm{ml}$ in a first test, $30 \mu \mathrm{g} / 100 \mathrm{ml}$ in a second, and $26 \mu \mathrm{g} / 100 \mathrm{ml}$ in a third test. PIPD between the first two tests, $100(30-35) /(30+35)=$ 
$-7.7 \%$, did not indicate a significant decrease (the $95 \%$ confidence interval for a decrease being $-13.6 \%$ ), but the difference between the third and first tests was significant.

The various tests of the HPA axis have usually been compared by observing the frequency of concordance between the responses concerning normality/subnormality. Such categories may be misleading in subjects in whom both responses are near the lower limit of normal. In tests involving release of endogenous ACTH the plasma cortisol response will depend on the state of the adrenal cortex. An appropriate method of evaluating such a response is to compare it with the cortisol response to the ACTH test. The PIPD method is useful for such comparisons.

In our series of patients with endogenous ACTH deficiency a highly significant correlation was observed between the responses to insulin and ACTH, as reported earlier by us (27) and by Kehlet et al. (22). If the presence of such endogenous ACTH deficiency is suspected, a subnormal response to the 2-hr ACTH test greatly strengthens the suspicion. On the other hand, a response in the high normal range (2-hr level $>45 \mu \mathrm{g} / 100 \mathrm{ml}$ in our series) serves to disprove such a suspicion. An even better concordance was observed between the ACTH and insulin tests in ACTH deficiency due to pharmacologic glucocorticoid medication and is also evident from the data of Daly et al. (9). Thus, the 2-hr ACTH test offers a simple means of following iatrogenic suppression of the HPA axis $(21,30)$.

In primary adrenocortical failure, single dose ACTH tests with measurement of plasma cortisol response at $0.5-2 \mathrm{hr}$ have been reported in 55 confirmed cases $(4,18,23,31,32,35,41)$. None of the subjects had a plasma cortisol increment $>3.0 \mu \mathrm{g} /$ $100 \mathrm{ml}$. This has been accepted as a basic diagnostic criterion for this disease. We have had an exceptional opportunity to follow subjects during the development of primary adrenocortical disease. Our experience proves that in the early stages this disease is indistinguishable from adrenocortical insufficiency secondary to diminished ACTH secretion. It is only later that the patient with primary Addison's disease (28) loses the increment. This suggests that there is a limit to the mass of adrenocortical tissue necessary for sufficient cortisol regulation. Only below this limit will endogenous ACTH secretion be maximally activated so that the response to additional exogenous $\mathrm{ACTH}$ is lost.

The ACTH test does not differentiate with certainty between primary and secondary (Fig. 5) adrenocortical failure, but if no cortisol substitution has been given a subnormal increment strongly suggests primary failure. In our experience this problem of differential diagnosis is not solved by a 4-day ACTH test either (to be published). Determination of plasma ACTH concentration may be necessary for that purpose.

\section{REFERENCES AND NOTES}

1. Abramowicz, M., Barnett, H. L., Edelmann, C. M., Jr., Greifer, I., Kobayashi, O., Arneil, G. C., Barron, B. A., Gordillo-P., G., Hallman, N., and Tiddens, H. A.: Controlled trial of azathioprine in children with nephrotic syndrome. Lancet, $i: 959$ (1970).

2. Alleyne, G. A., and Young, V. H.: Test of adrenocortical reserve in Children. Lancet, ii: 503 (1966)

3. Armitage, P.: Sampling errors in regression and correlation: Erros of Prediction. Statistical Methods in Medical Research, p. 163 (Blackwell Scientific Publications, Oxford, 1971).

4. Barnes, N. D., Joseph, J. M., Atherden, S. M., and Clayton, B. E.: Functional tests of adrenal axis in children with measurement of plasma cortisol by competitive protein binding. Arch. Dis. Childhood, 47: 66 (1972)

5. Birke, G., Diczfalusy, E., and Plantin, L.-O.: Assessment of the functional capacity of the adrenal cortex. I. Establishment of normal values. J. Clin. Endocrinol. Metab., 18: 736 (1958).

6. Bliss, E. L., Nelson, D. H., and Samuels, L. T.: Effects of intravenous ACTH on blood levels of 17 -hydroxycorticosteroids and circulating leukocytes. J. Clin. Endocrinol. Metab., 14: 423 (1954).

7. Blizzard, R. M., and Gibbs, J. H.: Candidiasis: Studies pertaining to its association with endocrinopathies and pernicious anemia. Pediatrics, 42: 231 (1968).

8. Churg, J., Habib, R., and White, R. H. R.: Pathology of the nephrotic syndrome in children. Lancet, $i: 1299$ (1970).

9. Daly, J. R., Myles, A. B., Bacon, P. A., Beardwell, C. G., and Savage, O.: Pituitary adrenal function during corticosteroid withdrawal in rheumatoid arthritis. Ann. Rheum. Dis., 26: 18 (1967).

10. Danowski, T. S., Hofmann, K., Weigand, F. A., and Sunder, J. H.: Steroid responses to ACTH-like polypeptides. J. Clin. Endocrinol. Metab., 28: 1120 (1968).

11. Davidson, A. G. F., and Johnston, C.: The Synacthen test of adrenal cortical function in children. Clin. Pediat., 7: 626 (1968).

12. Donald, R. A.: Plasma immunoreactive corticotrophin and cortisol response to insulin hypoglycemia in normal subjects and patients with pituitary disease. J. Clin. Endocrinol. Metab., 32: 231 (1971).

13. Eik-Nes, K., Sandberg, A. A., Nelson, D. H., Tyler, F. H., and Samuels, L. T.: Changes in plasma levels of 17-hydroxycorticosteroids during the intravenous administration of ACTH. I. A test of adrenocortical capacity in the human. J. Clin. Invest., 33: 1502 (1954).

14. Ely, R. S., Raile, R. B., Bray, P. F., and Kelley, V. C.: Studies of 17. hydrocorticosteroids. IV. Evaluation of a standard ACTH-17-hydrocorticosteroid response test in children. Pediatrics, 13: 403 (1954).

15. Feurle, G., Reisert, P.-M., Emrich, D., König, A., and Bushe, K.-A.: Untersuchungen zur klinischen und Endokrinologischen Diagnostik von Hypophysären und suprasellären Tumoren. Dtsch. Med. Wochenschr., 95: 1051 (1970).

16. Gaddum, J. H.: Lognormal distributions. Nature, 156: 463 (1945).

17. Girard, J., Baumann, J. B., Stahl, M., Nars, P. W., Bühler, U., and Wick, H.: Experience with insulin-induced hypoglycemia as a provocative test for growth hormone and cortisol secretion in children. Hormones, 2: 338 (1971).

18. Greig, W. R., Jasani, M. K., Boyle, J. A., and Maxwell, J. D.: Corticotrophin stimulation tests. Mem. Soc. Endocrinol., 17: 175 (1968).

19. Harris, E. K., and DeMets, D. L.: Estimation of normal ranges and cumulative proportions by transforming observed distributions to gaussian form. Clin. Chem., 18: 605 (1972).

20. Kappeler, H., and Schwyzer, R.: Die Synthese eines Tetracosapeptides mit der Aminosäuresequenz eines hochaktiven Abbauproduktes des $\beta$-Corticotropins (ACTH) aus Schweine-hypophysen. Helv. Chim. Acta, 44(2): $1136(1961)$.

21. Kehlet, H., and Binder, C.: Value of an ACTH test in assessing hypothalamicpituitary-adrenocortical function in glucocorticoid-treated patients. Brit. Med. J., 2: 147 (1973).

22. Kehlet, H., Blichert-Toft, M., Lindblom, J., and Rasmussen, P.: Short ACTH test in assessing hypothalamic-pituitary-adrenocortical function. Brit. Med. J., 1: 249 (1976).

23. Knappe, G.: Adrenocortical stimulation tests with ACTH: Developments and changes of a diagnostic procedure. Hormones, 2: 76 (1971).

24. Landon, J., James, V. H. T., Cryer, R. J., Wynn, V., and Frankland, A. W.: Adrenocorticotropic effects of a synthetic polypeptide $\beta^{1-24}$-corticotropin in man. J. Clin. Endocrinol. Metab., 24: 1206 (1964).

25. Laron, Z., Karp, M., Nitzan, M., and Perzelan, A.: The plasma 11-hydroxycorticosteroids response to insulin-induced hypoglycaemia in children and adolescents. Acta Endocrinol., 69: 451 (1969).

26. Leisti, S., and Perheentupa, J.: Insulin test: Precision of and correlations between glucose and hormone responses. Acta Endocrinol., 1978 (In press).

27. Leisti, S., and Perheentupa, J.: The precision and correlations of hypothalamic-pituitary-adrenocortical tests in children. Acta Paediat. Scand. 62: 86 (1973).

28. Leisti, S., and Perheentupa, J.: Two-hour ACTH test in the diagnosis of adrenocortical failure in children. Acta Paediat. Scand., 63: 323 (1974).

29. Leisti, S., and Perheentupa, J.: Critical evaluation of the 5-day metyrapone test. Horm. Res., 8: 1 (1977).

30. Leisti, S., Vilska, J., and Hallman, N.: Adrenocortical insufficiency and relapsing in idiopathic nephrotic syndrome of childhood. Paediatrics, 60: 1977).

31. Maynard, D. E., Folk, R. L., Riley, T. R., Wieland, R. G., Gwinup, G., and Hamwi, G. J.: A rapid test for adrenocortical insufficiency. Ann. Intern. Med., 64: 552 (1966).

32. Melby, J. C.: Assessment of adrenocortical function. N. Engl. J. Med., 285: 735 (1971).

33. Moncloa, F., Velezco, I., and Gutierrez, L. A.: One-hour intravenous ACTH test. J. Clin. Endocrinol. Metab., 26: 482 (1966).

34. Murphy, B. E. P.: Some studies of the protein-binding steroids and their application to the routine micro and ultramicro measurement of various steroids in body fluids by competitive protein-binding radioassay. J. Clin. Endocrinol. Metab., 27: 973 (1967)

35. Musa, B. U., and Dowling, J. T.: Rapid intravenous administration of corticotropin as a test of adrenocortical insufficiency. J. Amer. Med. Assoc., 201: 139 (1967).

36. Perheentupa, J., and Hiekkala, H.: Twenty cases of the syndrome of autoimmune endocrinopathy and candidiasis. Acta Paediat. Scand., 62 $110(1973)$

37. Rosenbloom, A. L., Savory, J., and Londono, J. H.: The half-hour synthetic 1-24 corticotropin test of adrenocortical reserve in children. J. Paediat., 79: 489 (1971).

38. Schuler, W., Schär, B., and Desaulles, P.: Zur Pharmakologie eines ACTHwirksamen, vollsynthetischen Polypeptids, des $\beta^{1-24}$ Corticotropins, Ciba 30920-Ba, Synacthen, Schweiz. Med. Wochenschr., 93: 128 (1963).

39. Smilo, R. P., and Forsham, P. H.: Diagnostic approach to hypofunction and hyperfunction of the adrenal cortex. Postgrad. Med., 46: 146 (1969).

40. Spencer-Peet, J., Daly, J. R., and Smith, V.: A simple method for improving the specificity of the fluorometric determination of adrenal corticosteroids in human plasma. J. Endocrinol., 31: 235 (1965). 
41. Wood, J. B., Frankland, A. W., James, V. H. T., and Landon, J.: A rapid test of adrenocortical function. Lancet, $i: 243$ (1965)

42. Zurbrügg, R. P., and Joss, E. E.: Diagnostic procedures in hypopituitary dwarfism. II. Evaluation of ACTH deficiency: Metopirone test, the daily oscillation of plasma cortisol and its response to exogenous ACTH, lysinvasopressin, insulin-induced hypoglycemia and general anesthesia. Helv. Paediat. Acta, 25: 382 (1970).

43. Informed consent was obtained from the parents of all children and from all adults included in this study.
44. The authors are grateful to Mr. Thorleif Johansson. B.Sc., and to Mrs. Arja Johansson, B.Sc., for valuable technical assistance.

45. Financial support from the Medical Research Council of the Academy of Finland, from the Foundation for Paediatric Research and from the Ane and Signe Gyllenberg Foundation is gratefully acknowledged.

46. Requests for reprints should be addressed to: S. Leisti, M.D., Lastenklinikka, SF-00290 Helsinki 29, Finland.

47. Received for publication January $18,1977$.

48. Accepted for publication July 27, 1977.

Copyright (C) 1978 International Pediatric Research Foundation, Inc.

Printed in U.S.A. 